\title{
RUIMTELIKE BEPLANNING: DIE ROL VAN DIE STADS- EN STREEKSBEPLANNER IN DIE SAW
}

\author{
Lt D. R. ERASMUS*
}

\begin{abstract}
Since 1978 regional and town planners are employed in the SADF on a permanent basis as well as in the capacity of national service men. These men are all academically qualified and as such satisfy a need that developed in the SADF for planning, in general.
\end{abstract}

It has namely, in the course of time become imperative that the SADF should have a say in the regional development actions of the various towns and regions of the RSA as it would be pointless for town and regional planners to reserve an area for private development if in future the SADF will require the area for its own development plans.

\section{Inleiding}

Daar word vandag algemeen aanvaar dat die bedreiging teen die RSA aan die toeneem is. Voortdurend kom daar waarskuwings vanuit die Parlement tydens sittings dat die RSA te make het met 'n totale aanslag teen hom. Die aanslag bestaan nie net uit fisiese konfrontasie nie, maar strek oor alle velde van die Suid-Afrikaanse gemeenskapslewe - die godsdienstige, ekonomiese, sosiaal-kulturele, maatskaplike terreine, ens. Militêre leiers bevestig dan ook telkens die gemelde waarskuwings en roep die bevolking en die SAW op tot paraatheid sodat die aanslag afgeweer kan word. Die toename in die bedreiging word op alle terreine voortdurend gemonitor om gepaste optredes daarteen te formuleer en uit te voer. Die strategiese beplanning in hierdie verband het, onder andere, grondgebruiksimplikasies omdat dit gepaard gaan met die vestiging van personeel en materieel op spesifieke gedeeltes grond (dit wil sê, in ruimtelike verband).

Die gevolg van die toename in die bedreiging was dat die SAW se betrokkenheid by aksies oor alle terreine, fenomenaal uitgebrei het. Nuwe velde moes betree word en selfs die blote fisiese groei van die SAW het hom in allerlei aksies van Staatsweë betrokke laat raak. Die bou van nasionale en provinsiale hoofpaaie het nie meer net politieke en sosiaal-ekonomiese doelwitte bevredig nie, maar het ook militêr-strategies van toenemende waarde geword.

Dieselfde geld ten opsigte van spoorlyne, lughaweris, hawens en dies meer. Tewens, die grootskaalse groei wat in die RSA plaasgevind het, het nuwe teikens vir die vyand daargestel wat weer beplanningsaksies deur die SAW genoodsaak het, ter beskerming daarvan. Vanselfsprekend het dit ook groei in getalle in die SAW veroorsaak wat weer fisiese groei in die onderskeie SAW-fasiliteite oor die hele binneland tot gevolg gehad het.

Ook op die landsgrense het die betrokkenheid van die SAW op alle vlakke toegeneem. Die nuwe Marxistiese regerings in Angola, Zimbabwe, en Mosambiek steun die magte wat die omverwerping van orde en stabiliteit in die RSA ten doel het en huisves insurgente. Die TEIN-operasies van die SAW het, aan die ander kant, ook vestiging deur die SAW op 'n permanente en niepermanente basis, op verskeie plekke op die landsgrense te weeg gebring.

\section{Die Nasionale Fisiese Ontwikkelings- plan (NFO) en ontwikkelinge voort- spruitend daaruit}

Gedurende 1975 het die destydse Departement van Beplanning die sogenaamde NFO gepubliseer wat die eerste bloudruk verteenwoordig het ten opsigte van die langtermyn fisiese ontwikkeling van die RSA op nasionale vlak. Hierdie ontwikkelingsplan het die desentralisasie-beleid van die Regering, fisiese ontwikkeling op daardie stadium, ekonomiese en sosiale ontwikkelingstendense, in ag geneem en 'n langtermyn fisiese ontwikkelingstruktuur vir die RSA daargestel. Hierdie plan is grootliks deur stads- en streeksbeplanners van die betrokke Departement daargestel. In terme hiervan sou die PretoriaWitwatersrand-Vereeniging gebied (PWV), die 


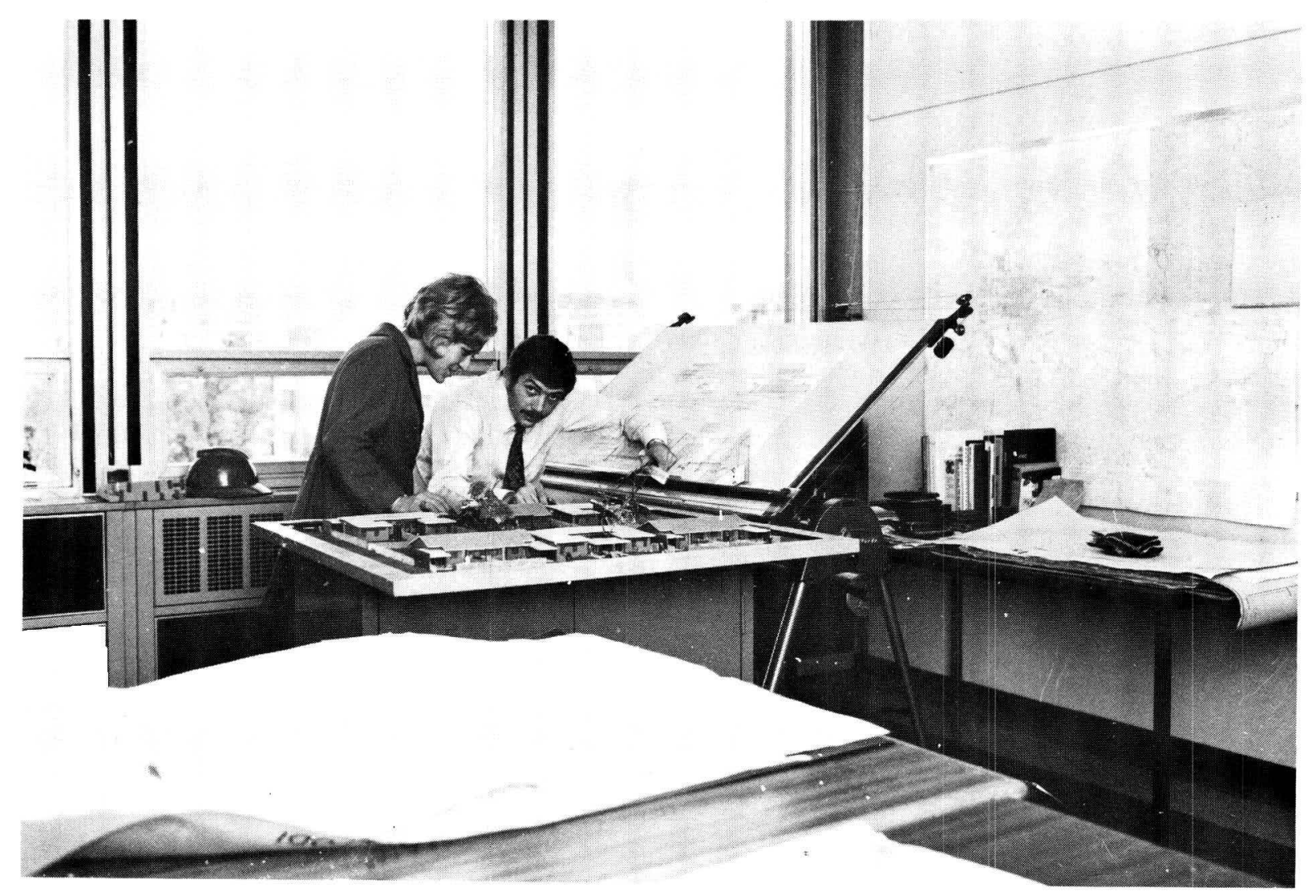

Stads/Streeksbeplanners aan die werk. Foto's: Munitoria

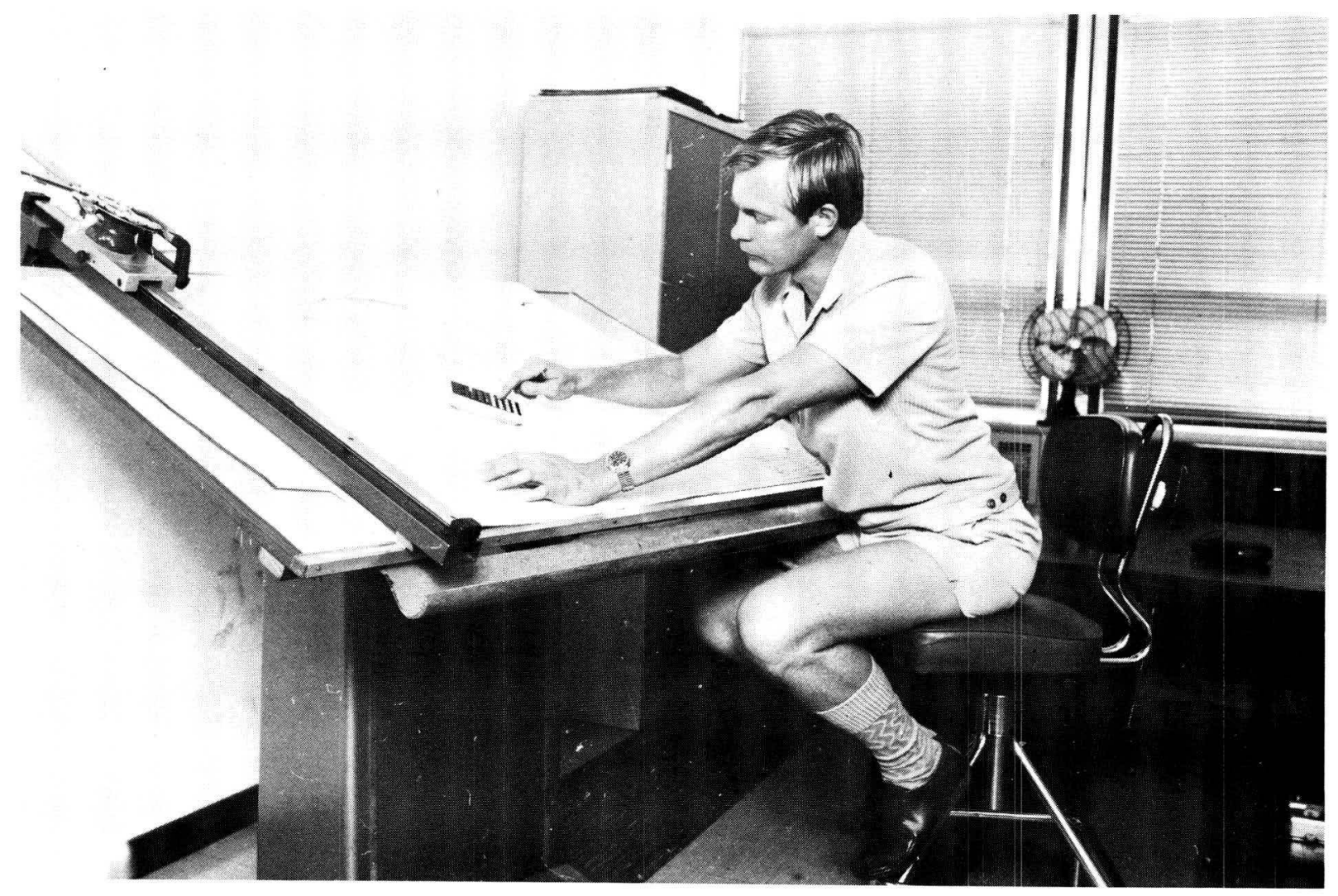


dominante kern in die RSA bly terwyl DurbanPinetown, Port Elizabeth-Uitenhage en die Kaapse Skiereiland as metropolitaanse gebiede behoue sou bly. Bykomend sou Richardsbaai, Saldanha en Oos-Londen ook tot metropolitaanse skaal uitgebou word. Die RSA is ook verder in agt-en-dertig ontwikkelingstreke, uitgesonderd die metropolitaanse gebiede en tuislande, verdeel ten opsigte waarvan streeksontwikkelingsplanne opgestel moes word. Die NFO is egter opgestel sonder enige militêr-strategiese insette deur die SAW. Streeksontwikkelingsplanne wat later opgestel moes word, het ten doel om 'n ontwikkelingstrategie vir die onderskeie streke op te stel sodat ontwikkeling aldaar beide gestimuleer en ruimtelik gerig word. Gidsplanne, wat op stadsvlak opgestel word, het weer ten doel om oorhoofs aan te dui waar die Staat gespesifiseerde ontwikkeling sal toelaat sodat die stad of dorp binne daargestelde riglyne kan ontwikkel, gewoonlik in ' $n$ periode van tussen twintig tot vyf-en-twintig jaar.

Die streeksbeplanningsaksies ten opsigte van verskeie streke van die RSA soos ingedeel in die NFO, asook die instelling van statutêre gidsplanne vir dorpe en stede, het meegebring dat die SAW ook insette moes formuleer vir die opstel van die onderskeie planne. Dit sou byvoorbeeld geen doel dien om 'n gebied vir privaatontwikkeling op ' $n$ streeks- of gidsplan te reserveer indien die SAW vestiging daarop beoog. nie. Die formulering van insette was aan die een kant 'n gespesialiseerde taak wat insette deur stads- en streeksbeplanners (wat gekwalifiseer is vir hierdie taak) vereis het tesame met noodsaaklike informasie wat noodwendig deur militêre spesialiste verskaf moes word. Dit was dan ook spesifiek gedurende hierdie tydperk dat die waarde van stads- en streeksbeplanners as professionele lui vir die SAW, besef is en sedert 1978 is verskeie stads- en streeksbeplanners as permanente staf en nasionale dienspligtiges in die SAW gebruik vir die formulering van vestigingsbeleid in die algemeen, en ten opsigte van sekere dorpe, stede en gebiede in die besonder.

\section{Die Afdeling Logistiek as tuiste vir Stads- en Streeksbeplanners}

Gedurende 1978 is die Direktoraat Logistiese Beplanning van die Afdeling Logistiek van die SAW belas met die taak om namens die SAW aan streeksbeplannings- en gidsplanaksies deel te neem. Onder leiding van bekwame militêre toesig, is die insette van stads- en streeksbeplan- ners geharmonieer met die nodige militêre kennis en insig en is waardevolle samewerking met die betrokke Staatsdepartemente bewerkstellig. Terselfdertyd is verseker dat insette wat deur die SAW gelewer moes word, ten alle tye in ag geneem is in die vooruitbeplanningsaksies van Staatsdepartemente, Provinsiale Administrasies, Plaaslike Besture (Munisipaliteite) en die privaatsektor. Dié vooruitbeplanningsaksies akkommodeer dus huidige en verwagte SAW-behoeftes sodat die SAW-grondgebruike op die langtermyn komplementerend in plaas van botsend sal wees ten opsigte van die aangrensende grondgebruike, wat dit ookal mag behels.

Die ondervinding wat stads- en streeksbeplanners opdoen in die Direktoraat Logistiese Beplanning strek oor soveel terreine van die beplanningsveld dat die Suid-Afrikaanse Instituut vir Stads- en Streeksbeplanning hierdie ondervinding in ag neem by die toekenning van korporaatlidmaatskap van die Instituut - die hoogste vorm van lidmaatskap. Lede van die Instituut het dan ook al by verskeie geleenthede hulle dankbaarheid te kenne gegee oor die wyse waarop die SAW stads- en streeksbeplanners aanwend en professioneel benut tot voordeel van die SAW in die eerste plek, maar ook die stadsen streeksbeplanningsberoep in die RSA as geheel.

In die tgeval van dienspligtiges is die huidige reëlings dat stads- en streeksbeplanners na die onderskeie opleidingseenhede gaan vir hulle aanvanklike basiese militêre opleiding. Indien hulle gekeur word vir offisiersopleiding, moet die nodige opleiding in hierdie verband ook ondergaan word. Na voltooiing hiervan, word hulle na die Afdeling Logistiek uitgeplaas waar hulle dan hulle militêre diensplig moet voltooi. $\mathrm{Na}$ 'n aanvanklike opleidingsperiode waarin hulle touwys gemaak word om die onderskeie militêre grondgebruike te identifiseer asook die toepaslike probleme, ens, word hulle in die Afdeling Logistiek op sterkte gehou en word vandaar afgedeel na die onderskeie gevegs- en ondersteuningsdienste waar hulle dienste benodig word. Die onderskeie dienste kan getuig van die nuttige rol wat stads- en streeksbeplanners in die verlede en tans, daar vervul het.

\section{Faktore wat die aanwending van stads- en streeksbeplanners in die SAW moontlik maak}

Die eerste rede waarom stads- en streeksbeplanners as professionele lui in die SAW aangewend 
kan word, spruit voort uit hulle akademiese opleiding. Hulle opleiding strek oor 'n wye veld en het ten doel om hulle toe te rus vir algemene beplanningstake, maar fisiese beplanning in die besonder. Benewens teoretiese en praktiese onderrig wat gewoonlik oor 'n vier jaar periode strek, in die vakke Stadsbeplanning en Streeksbeplanning, ontvang hulle onderrig in die volgende vakinrigtings: Ekonomie, Sosiologie, Geografie en Statistiek. Aanverwante onderrig in Vervoeringenieurswese, Omgewingsingenieurswese, Vervoerbeplanning, Ekonomie van Grondgebruik en Beplanningsreg word ook aangebied. Hierdie wye akademiese opleiding maak die persone geskik om aangewend te word vir die beplanning van SAW grondgebruike op nasionale (RSA)-, streeks-, kommandements- en detailvlak.

Die tweede faktor spruit voort uit die behoefte wat in die RSA ontstaan het in die sestigerjare aan beplanning in die algemeen. Die fisiese ontwikkeling voor hierdie tydperk was wel relatief vinnig maar die versnelling in die ontwikkelingstempo na Republiekwording het veroorsaak dat langtermyn vooruitbeplanningsaksies genoodsaak was deur Staatsdepartemente (soos die SAW, SAS \& H, ens), Provinsiale Administrasies, Plaaslike Besture en die privaatsektor. Vanweë die toenemende verstedeliking en gevolglike fisiese groei van stede, het botsende grondgebruike al hoe meer ontstaan namate die aansprake op grond en die gebruik daarvan, toegeneem het. Grond wat vir baie jare lank sonder enige probleme vir militêre doeleindes aangewend was, het in 'n toenemende mate onder druk gekom vir ander gebruike of die doeltreffende gebruik daarvan is belemmer deur verkeersopeenhopings, besoedeling, die ontwikkeling van dorpsgebiede op die grense, die bou van snelweë, ens. So ondervind Waterklooflughawe alreeds probleme weens sy ligging langs groot deurpaaie en woongebiede wat byna op sy grense ontstaan het. Die hele Voortrekkerhoogtegebied word tans ook deur 'n verskeidenheid van groot orde paaie deurkruis wat toegangs- en sekerheidsprobleme veroorsaak. Daar kan tewens met reg gekonstateer word dat baie bestaande SAW fasiliteite wat huidiglik moontlik geen of geringe probleme ondervind, in die toekoms groot of groter probleme gaan hê weens die ligging daarvan in of langs stedelike konsentrasies. Die vroegtydige identifisering van sodanige gebiede asook die oplossing van die probleme, waar moontlik, is aspekte wat binne die werksterrein van die stads- en streeksbeplanner val. Dit is egter logies dat hy in die oplossing van probleme, afhanklik is van die insette van ervare militêre personeel op alle vlakke.

\section{Slot}

Uit die voorafgaande beskrywing is dit duidelik dat stads- en streeksbeplanners ' $n$ nuttige funksie in die SAW vervul. Dit geld ten opsigte van beide Staandemag-lede van die SAW en dienspligtiges. Vir Staandemag-lede hou die toekoms veral velerlei uitdagings in. Daar is talle aspekte ten opsigte waarvan navorsing nog gedoen of beleid geformuleer moet word. So is 'n spesifieke aspek byvoorbeeld wat die invloed is van die vestiging van SAW-fasiliteite op 'n groot skaal by kleiner plattelandse dorpe soos Hoedspruit en Phalaborwa, en hoe hierdie grootskaalse vestigings tot die beste mate geharmonieer kan word met die omliggende gebruike. Soveel ander Staatsdepartemente kom met voorskrifte in hierdie verband dat vestigingsaksies wat soms dringend van aard is, vertraag word. Indien die SAW oor navorsingsresultate in hierdie verband beskik, kan hy die vereistes van ander instansies na behore ondersoek en wetenskaplik daaroor verslag doen. Onnodige aanpassings en vertragings kan dan ook vermy word. In Amerika is sulke studies reeds onderneem en word dit in ag geneem by hulle vestigingsaksies.

Vir nasionale dienspligtiges hou die huidige opset ten opsigte van die aanwending van stads- en streeksbeplanners baie voordele in. Die groot koste verbonde aan hulle Universitêre opleiding wat grootliks deur die Staat gedra moet word, word onmiddellik omgesit in 'n rentedraende opbrengs wanneer hulle in hulle professionele hoedanigheid deur die SAW benut word. Verder het hulle unieke geleenthede om hulle praktiese kennis en ondervinding uit te brei en ter selfdertyd iets nuttig vir hulle land te beteken. Dit is dan ook geen wonder nie dat soveel stads- en streeksbeplanners wat reeds hulle diensplig voltooi het, met groot bewondering terugdink aan die nuttige funksie wat hulle kon vervul en nog steeds vervul omdat hulle vir nog 'n geruime tydperk, waardige Burgermaglede in diens van die SAW wil wees.

Dit is dan ook juis een van die byvoordele wat opgesluit lê in die benutting van stads- en streeksbeplanners as professionele lui deur die SAW, naamlik dat hierdie persone uiteindelik in die Staat- en private sektor opgeneem word en nuttige kontakpunte vir die SAW vorm. Omdat hulle die behoeftes van die SAW oor verskeie 
fronte ken, kan hulle dus ook in hulle private hoedanighede, uiteindelik begrip toon vir die behoeftes van die SAW in daardie Staatsdepartemente, Plaaslike Besture of private praktyke waar hulle uiteindelik werk na voltooiing van hulle dienspligtydperk. Verder bring dit mee dat die SAW se behoeftes in ag geneem word op hoë vlakke soos in beplanningsaksies in die Kantoor van die Eerste Minister, Departemente van Gemeenskapsontwikkeling, Samewerking en Ontwikkeling, Plaaslike Bestuur en die onderskeie munisipaliteite waar stads- en streeksbeplanners werksaam is.

* Lt D. R. Erasmus, BA, BSc(S\&S) is ' $n$ dosent in die Departement Opmeetkunde en Stads- en Streeksbeplanning in die Fakulteit Ingenieurswese aan die Universiteit van Pretoria. 